Situs Jurnal : $\underline{\text { http://ejournal.stiepancasetia.ac.id/index.php/jieb }}$

Jilid 5 Nomor 2 Juli 2019

Hal $246-255$

\title{
ANALISIS PENGENDALIAN PERSEDIAAN BAHAN BAKU PADA PABRIK TAHU SKM DI BANJARBARU
}

\section{Imawati Yousida*}

Abstract: The purpose of this study was to determine the analysis of production cost collection at the SKM Tofu Factory in Banjarbaru and to apply the Economic Order Quantity (EOQ) method. This study is a research study by collecting data with documentation techniques and data used is secondary data in the form of material inventory raw soybeans and other costs. Continuing with these data so that the production process can run smoothly by fulfilling the raw material inventory needs, namely by applying raw material inventory control using the Economic Order Quantity (EOQ) method. The results showed that the SKM Tofu Factory could save the purchase of raw materials for soybeans by Rp 129,132,512.5, - Analysis of raw material inventory control using the Economic Order Quantity (EOQ) Method. the results of the application of the method obtained EOQ value with a total quantity of 2,908 $\mathrm{Kg}$ per month for January each time ordering and the frequency of ordering 5 times a month. Raw material inventory (SS) is $11,124.38 \mathrm{Kg}$ per month, the maximum inventory (MI) is $10,293.72 \mathrm{Kg}$ and the Total Supply Cost is Rp. 1,325,854,300. Savings on inventory control using the EOQ method is Rp 129,132,512.5 when using this method

Keywords: Inventory , Tofu Factory, EOQ

Abstrak: Tujuan dari penelitian ini adalah Untuk mengetahui analisis pengumpulan biaya produksi pada Pabrik Tahu SKM di Banjarbaru dan menerapkan metode Economic Order Quantity (EOQ) Penelitian ini adalah penelitian studi dengan mengumpulkan data dengan teknik dokumentasi dan data yang digunakan adalah data sekunder berupa pembelian persediaan bahan baku kacang kedelai dan biaya lainnya. Selanjutkan dengan data tersebut agar proses produksi dapat berjalan lancar dengan pemenuhan kebutuhan persediaan bahan baku yaitu dengan menerapkan pengendalian persediaan bahan baku menggunakan metode Economic Order Quantity (EOQ). Hasil penelitian menunjukkan bahwa Pabrik Tahu SKM dapat menghemat pembelian bahan baku kacang kedelai sebesar Rp 129.132.512,5,- Analisis pengendalian persediaan bahan baku dengan menggunakan Metode Economic Order Quantity ( EOQ). hasil dari penerapan metode tersebut didapat nilai EOQ dengan jumlah kuantitas sebanyak $2.908 \mathrm{Kg}$ perbulan untuk bulan Januari setiap kali melakukan pemesan dan frekuensi pemesanan sebanyak 5 kali dalam sebulan. Pengaman persediaan ( SS) bahan baku sebanyak 11.124.38 Kg rata rata perbulan, persediaan maksimum (MI) adalah sebanyak $10.293,72 \mathrm{Kg}$ dan Total Biaya Persaediaan sebesar Rp 1.325.854.300. Penghematan atas pengendalian persediaan dengan metode EOQ adalah sebesar Rp 129,132,512.5 apabila menggunakan metode tersebut.

Kata kunci : Persediaan, Perusahaan Tahu, EOQ 


\section{Latar Belakang}

Dalam kegiatan produksi pada perusahaan manufaktur dalam proses produksi harus didukung dengan pemenuhan kebutuhan dalam pengendalian persediaan cukup.salah satu cara pengendalian persediaan merupakan cara untuk menghemat dan mencegah pemborosan dan akan mengakibatkan penurunan laba karena biaya yang besar atau tak terkendali,

Proses produksi berjalan efektif dan efisien, pengawasan dan pengendalian persediaan menjadi masalah yang sangat penting karena jumlah persediaan akan menentukan atau mempengaruhi kelancaran produksi perusahaan tersebut. Jumlah atau tingkat persediaan yang dibutuhkan oleh perusahaan berbeda-beda untuk setiap perusahaan, pabrik, tergantung dari volume produksinya, jenis pabrik dan prosesnya.

Pengendalian persediaan merupakan salah satu fungsi manajemen yang dapat dipecahkan dengan menerapakan metode kuantitatif. Teknik pengendalian persediaan merupakan tindakan yang sangat penting dalam menghitung berapa jumlah optimal tingkat persediaan yang diharuskan, serta kapan saatnya mengadakan pemesanan kembali.

Metode EOQ berusaha mencapai tingkat persediaan yang seminimum mungkin, biaya rendah dan mutu yang lebih baik. Perencanaan metode EOQ dalam suatu perusahaaan akan mampu meminimalisir terjadinya out of stock sehingga tidak mengganggu proses dalam perusahaan dan mampu menghemat biaya persediaan yang dikeluarkan oleh perusahaan karena adanya efisisensi persediaan bahan baku di dalam perusahaan yang bersangkutan. Selain itu dengan adanya penerapan metode EOQ perusahaan akan mampu mengurangi biaya penyimpanan, penghematan ruang, baik untuk ruangan gudang dan ruangan kerja, menyelesaikan masalah-masalah yang timbul dari banyaknya persediaan yang menumpuk sehingga mengurangi resiko yang dapat timbul

Pabrik Tahu SKM di Banjarbaru adalah kegiatab usaha manufaktur yaitu memproduksi tahu dengan dua jenis yaitu tahu putih dan tahu goreng. Bahan baku utama pada produksi pabrik tahu SKM di Banjarbaru adalah memakai kacang kedelai. seiring perkembnag nya produk makanan jadi, tahu menjadi bahan dasar produk makanan atau tambahan berbahan tahu. Persediaan bahan baku perlu diperhatikan dalam dalam penyimpanan, perlu ada perhatian khusus agar kualitas tahu yang diproduksi bagus dan awet. Beberapa hal yang mempengaruhi hasil produksi adalah kualitas kacang kedelai yang dipakai. kacang kedelai yang dipakai pabrik tahu SKM adalah kualitas impor dan perlu perhatian khusus untuk ancaman hewan seperti tikus dan kelembaban gudang . Dari permintaan tahu dari bulan ke bulan dilihat cenderung meningkat karena usaha yang semakian berkembang, otomatis pemesan persediaan bahan baku juga akan meningkat dan menambah biaya pemesanan dan juga biaya pemeliharaan.

Seharusnya dengan adanya kebijakan persediaan bahan baku yang diterapkan dalam perusahaan, biaya persediaan tersebut dapat ditekan sekecil. Untuk meminimumkan biaya persediaan tersebut dapat digunakan analisis Economic Order Quantity (EOQ). EOQ adalah volume atau jumlah pembelian yang paling ekonomis untuk dilakukan pada setiap kali pembelian. Berdasarkan data persediaan bahwa setiap bulan Januari sampai dengan bulan Desember 2018 mengalami peningkatan terhadap jumlah pembelian bahan baku kacang kedelai yang dilakukan pabrik tahu SKM di Banjabaru.

Pengendalian persediaan bahan baku dapat menggunakan metodel pembelian yang optimal atau Economic Order Quantity (EOQ). dapat diketahui seberapa besar kuantitas dan frekuensi pemesanan bahan baku kacang kedelai. melakukan persiapan Persediaan bahan pengaman (safety stock) Persediaan pengamanan adalah persediaan tambahan yang diadakan untuk melindungi atau menjaga kemungkinan terjadinya kekurangan bahan (stock out). Selain digunakan untuk menanggulangi terjadinya keterlambatan datangnya bahan baku. Agar dalam pemesanan tepat waktu perlu diketahui berapa sisa bahan baku yang digunakan sampai batas 
waktu pesanan datang yaitu Reorder point (ROP). Batas persediaan yang ada digunakan dengan menggunakan Maksimal Inventory (MI) jadi tidak ada pemborosan tempat dan biaya serta biaya pemesanan.

Berdasarkan uraian di atas pada pabrik tahu SKM di Banjarbaru dalam menjalankan kegiatan produksinya dari bulan ke bulan mengalami peningkatan dan permasalahan yang ada pabrik tahu SKM belum pernah membuat data biaya produksi dan belum memperhatikan dan memperhitungkan perencanaan persediaan bahan baku. Berdasarkan berbagai uraian latar belakang di atas dapat diambil judul : Analisis Pengendalian Persediaan Bahan Baku menggunakan Metode Economic Order Quantity (EOQ) pada Pabrik Tahu SKM di Banjarbaru".

\section{Kajian Literatur}

Akuntansi biaya adalah proses pencatatan, penggolongan, peringkasan dan penyajian biaya, pembuatan dan penjualan produk atau jasa, dengan cara-cara tertentu, serta penafsiran terhadapnya. Dalam perusahan manufaktur ada 3 fungsi pokok, yaitu fungsi produksi, fungsi pemasaran dan fungsi administrasi dan umum. Oleh karena itu dalam perusahaan manufaktur, biaya dapat dikelompokan menjadi 3 yaitu biaya produksi, biaya Administrasi dan biaya pemasaran. Harga pokok produksi meliputi keseluruhan bahan langsung, tenaga kerja langsung, dan overhead pabrik yang dikeluarkan untuk memproduksi barang atau jasa. Harga pokok produksi terdiri atas tiga komponen utama, yaitu:

1. Bahan baku langsung yang meliputi : biaya pembelian bahan, potongan pembelian, biaya angkut pembelian, biaya penyimpanan, dan lain-lain.

2. Tenaga kerja langsung yang meliputi semua biaya upah karyawan yang terlibat secara langsung dalam proses pembuatan bahan baku menjadi barang jadi atau barang yang siap dijual.

3. Biaya overhead pabrik meliputi semua biaya-biaya diluar dari biaya perolehan biaya bahan baku langsung dan upah langsung

Persediaan (Inventory) adalah stok dari suatu item atau sumber daya yang digunakan dalam suatu organisasi perusahaan klasifikasi persediaan sebagai cadangan bahan mentah yang dimiliki oleh perusahaan memiliki beberapa macam karakteristik yang dibedakan berdasarkan fungsi dan kegunaannya. Jenis persediaan dapat dibedakan menjadi:

1. Persediaan bahan mentah (raw material),

2. Persediaan bahan pembantu atau penolong (supplies),

3. Persediaan barang dalam proses (work in process

4. Persediaan barang jadi (finished goods),

Biaya persediaan merupakan sejumlah dana yang akan dikeluarkan oleh perusahaan guna mendapatkan persediaan bahan baku yang dibutuhkan. Biaya persediaan harus dipersiapkan dan direncanakan secara maksimal oleh pengelola guna menghindari adanya biaya yang terbuang sia-sia. Unsur-unsur biaya yang terdapat dalam persediaan dapat digolongkan menjadi tiga, yaitu:

1. Biaya Pemesanan

2. Biaya Penyimpanan

3. Biaya Kekurangan Persediaan: Tertundanya penjualan, Kehilangan penjualan, Kehilangan Pelanggan 
Perencanaan Pengendalian Persediaan dengan menggunakan metode Economic Order Quantitative (EOQ) yaitu Pembelian bahah baku harus diperhitungkan dengan hatihati.Perusahaan harus memperhatikan arus keluar masuk dana yang dipergunakan guna meningkatkan efektivitas serta efisiensi arus keuangan perusahaan. Pemesanan bahan baku perusahaan harus melalui prose yang panjang dan har mengeluarkan biaya seminimal mungkin dan seekonomis mungkin. EOQ (Economic Order Quantity) adalah jumlah kuantitas barang yang dapat diperoleh dengan biaya yang minimal, atau sering dikatakan sebagai jumlah pembelian yang optimal. Untuk memenuhi kebutuhan tersebut maka dapat diperhitungkan pemenuhan kebutuhan pembeliannya yang paling ekonomis yaitu sejumlah barang yang akan dapat diperoleh dengan pembelian menggunakan biaya yang minimal.

Kebanyakan literatur persediaan mengatakan bahwa, model EOQ sangat mudah untuk diterapkan apabila asumsi dasar dalam EOQ dipenuhi sebagai berikut:

1. Permintaan dapat ditentukan secara pasti atau konstan. Yaitu dimana tingkat permintaan untuk setiap item bersifat konstan dan diketahui dengan pasti untuk penggunaan satu tahun atau satu periode.

2. Item yang dipesan independen dengan item lain. Yaitu persediaan permintaan item yang dipesan bebas dengan item lain atau item adalah produk satu macam dan tidak ada hubungan dengan produk lain.

3. Pesanan diterima dengan segera dan pasti. Yaitu persediaan dari pesanan tiba dalam satu batch atau paket pada satu titik waktu dan pesanan datang pada waktu yang bersamaan dan tetap.

4. Tidak terjadi stockout. Yaitu tidak terjadi adanya kekurangan atau kehabisan stock pasokan barang dengan permintaan barang karena model EOQ tidak diijinkan hal tersebut.

5. Harga item konstan. Yaitu dimana harga bahan baku konstan atau tidak terjadi perubahan selama satu periode tertentu, dengan kata lain harga per unit tetap dan tidak ada pengurangan harga walaupun pembelian dalam jumlah volume yang besar.

Perhitungan Economic Order Quantitative (EOQ) adalah Untuk menentukan pemesanan bahan baku diperlukan perhitungan yang sangat teliti dan hati-hati. Dalam teori ekonomi perhitungan pemesanan bahan baku secara efektif atau economic order quantitative dapat dilakukan dengan menggunakan rumus perhitungan EOQ yaitu:

$E O Q=\frac{2 \times R \times S}{C}$

$\mathrm{R}=$ Jumlah yang dibutuhkan selama satu periode tertentu misalkan 1 tahun.

$\mathrm{S}=$ Biaya pesanan tiap kali pesan.

$\mathrm{P}=$ Harga pembelian perunit yang dibayar.

$\mathrm{C}=$ Biaya penyimpanan dan pemeliharaan digudang dinyatakan dalam presentase dari nilai rata-rata dalam rupiah dari persediaan

Grafik persediaan dalam model ini berbentuk gigi gergaji, karena permintaan dianggap konstan, persediaan berkurang dalam jumlah yang sama (linear) dari waktu ke waktu. Pada saat tingkat persediaan mencapai nol, pesanan untuk kelompok baru tepat diterima, sehingga tingkat persediaan naik kembali sampai Q. 


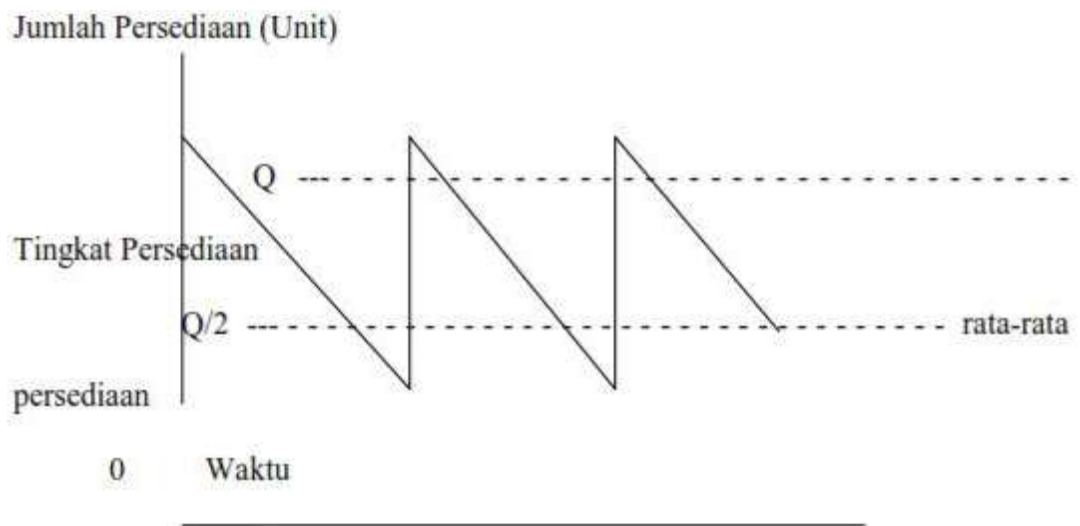

\section{Gambar 1. Grafik Persediaan}

Nilai Q yang optimal/ ekonomis dapat diperoleh dengan menggunakan tabel dan grafik atau dengan menggunakan rumus/ formula. Cara Formula: Dalam metode ini digunakan beberapa notasi sebagai berikut:

D : Jumlah kebutuhan barang (unit/tahun)

$\mathrm{S}$ : Biiaya pemesanan atau biaya setup (rupiah/pesanan)

$\mathrm{H}$ : Biaya penyimpanan (\% terhadap nilai barang)

$\mathrm{C}$ : Harga barang (rupiah/unit)

$\mathrm{H}$ : Biaya penyimpanan (rupiah/unit/tahun)

Q : Jumlah pemesanan (unit/pesanan)

Tahapan Analisis dengan Economic Order Quantity (EOQ) dilakukan dengan menggunakan rumus sebagai berikut:

1. Safety Stock (SS) Rumus:

$\mathrm{SS}=$ Kebutuhan bahan baku / hari $\mathrm{x}$ jarak waktu yang diisyaratkan perusahaan

$\mathrm{C}=$ Biaya penyimpanan dan pemeliharaan

2. Reorder point (ROP) Rumus :

$\mathrm{ROP}=\mathrm{SS}+($ Lide time $\mathrm{x}$ kebutuhan bahan baku / hari $)$

3. Maximum Inventory (MI) Rumus :

$\mathrm{MI}=\mathrm{SS}+$ Freq EOQ

4. Perbandingan data sebelum dan sesudah menerapkan metode EOQ.

Perhitungan penggunaan bahan baku secara konvensional atau sebelum menggunakan metode Economic Order Quantitative dibandingkan dengan hasil dari perhitungan penggunaan bahan baku dengan menggunakan metode Economic Order Quantitative. Setelah diketahui hasil dari kedua metode tersebut maka akan didapatkan

Melihat proses pembelian bahan baku dan kebutuhan akan persediaan bahan baku untuk sertiap produksi maka dapat diejlaskan kerangka berpikir pada gambar 2 . 


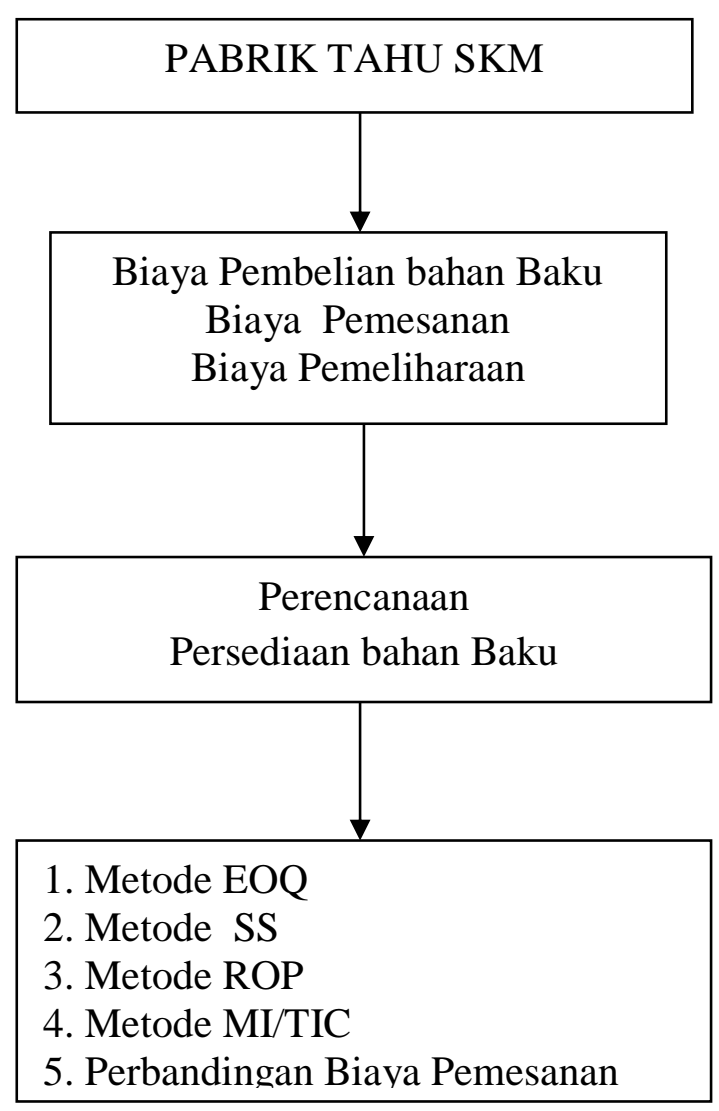

\section{Gambar 2. Kerangka Berfikir}

\section{Metode Penelitian}

Jenis penelitian yang digunakan dalam penelitian ini adalah penelitian kualitatif dengan desain penelitian deskriptif. Metode kualitatif digunakan untuk mendapatkan data yang mendalam, suatu data yang mengandung makna atau data yang sebenarnya. Dengan metode analisis yang digunakan untuk memperoleh gambaran .

Data kuantitatif yaitu data yang dinyatakan dalam bentuk angka. Berupa data yang berasal dari Pabrik Tahu SKM mengenai biaya pembelian bahan baku, biaya penyimpanan bahan baku dan biaya pesan bahan baku kacang kedelai Data kualitatif yaitu data yang dinyatakan dalam bentuk kata, kalimat, dan gambar. Berupa hasil wawanca dan observasi yang ada di Pabrik Tahu SKM.

Pengumpulan data yang dilakukan oleh penulis untuk mendukung penelitian ini membutuhkan data yang relevan sebagai berikut dengan cara Wawancara yaitu tanya jawab yang dilakukan baik secara langsung berhadapan dengan yang diwawancarai maupun secara tidak langsung. Penelitian keperpustakaan mempelajari buku literatur, jurnal penelitian, penelitian terdahulu, Observasi dengan turun kelapangan untuk mengamati perilaku dan aktivitas terkait dengan persediaan bahan baku yang terjadi pada pabrik Tahu SKM.

Berdasarkan permasalahan yang ada terkait dengan pengendalian persediaan bahan baku - Penerapan Metode Economic Order Quantity (EOQ) sebagai tindakan pengendalian persediaan bahan agar tetap dapat tersedianya bahan baku tersebut untuk proses produksi dan 
pemenuhan permintaan produk Tahu maka langkah langkah nya dengan melalui tahapan sebagai berikut:

1. Menghitung Nilai Economic Order Quantity (EOQ)

2. Menghitung frekuensi pembelian

3. Menghitung persediaan pengaman (safety stock)

4. Menghitung pemesanan kembali (reorder point)

5. Biaya total persediaan

6. Membandingkan perhitungan yang disarankan dengan kebijakan Pabrik

\section{Hasil Penelitian dan Pembahasan}

Industri Pabrik Tahu ini didirikan secara turun temurun dari keluarga, dimulai dari48 tahun yang lalu tepatnya pada tahun 1970 oleh bapak H. Mashuri yang berlokasi di Jalan Sutoyo, Banjarmasin, setelah 25 tahun berjalan atau pada saat tahun 1995 pabrik tersebut dipindahkan ke Jalan Suka Mara di Banjarbaru dikarenakan kondisi jalan yang sempit hingga mengakibatkan alat transportasi pengangkut bahan baku mengalami kesulitan untuk menuju kelokasi pabrik.

Proses Produksi Secara garis besar proses Pembuatan tahu SKM pembuatan tahu SKM sebagai berikut

1. Perendaman dan Pencucia

2. Penggiling

3. Perebusan / Pemasakan

4. Penyaringan

5. Proses Pengendapan

6. Pencetakan dan Pengepresan

7. Pemotongan tahu.

8. Penggorengan

Perencanaan Persediaan Bahan Baku kacang Kedelai Pabrik Tahu SKM masih menggunakan metode konvensional dalam melakukan perhitungan biaya bahan baku. Berikut adalah pembelian bahan

Pabrik Tahu SKM selama ini hanya melakukan pencatatan persediaan bahan baku secara sederhana. secara konvensional maka pabrik tahu ini hanya membutuhkan perhitungan tiga macam komponen yaitu,

1. Pembelian

2. Biaya pemesanan

3. Biaya penyimpanan. berikut :

Proses pengendalian persediaan bahan baku dilakukan dengan langkah-langkah sebagai

1. Menentukan nilai EOQ dengan Metode Economic Order Quantity

2. Perhitungan persediaan pengaman (safety stock),

3. Penentuan pemesanan kembali (reorder point)

4. Penentuan persediaan maksimal (maximum inventory),

5. Perhitungan biaya total persediaan.

Hasil perhitungan dengan menggunakan perencanaan pengendalian Metode EOQ ditunjukkan pada Tabel 1 . 
Tabel 1. Perbandingan Frekuensi dan Jumlah Pembelian Bahan Baku Berdasarkan Metode EOQ Periode Januari s.d Desember 2018

\begin{tabular}{|c|c|c|c|c|c|c|c|}
\hline \multirow{3}{*}{ Bulan } & \multirow{2}{*}{\multicolumn{2}{|c|}{$\begin{array}{l}\text { Frekuensi } \\
\text { Pembelian }\end{array}$}} & \multirow{2}{*}{\multicolumn{3}{|c|}{ Pembelian (Kg) }} & \multicolumn{2}{|c|}{ Jumlah Total Pembelian (Kg) } \\
\hline & & & & & & \multirow[t]{2}{*}{ Pabrik } & \multirow[t]{2}{*}{ EOQ } \\
\hline & Pabrik & EOQ & Pabrik & & EOQ & & \\
\hline Januari & 2 & 5,12 & 13.700 & & $2.675,9 \mathrm{Kg}$ & $105,196,750$ & 100.346 .250 \\
\hline Februari & 2 & 5 & 14.000 & & $2.800,0 \mathrm{Kg}$ & $112,710,750$ & 105.000 .000 \\
\hline Maret & 2 & 5,09 & 14.500 & & $2.849,6 \mathrm{Kg}$ & $112,710,750$ & 108.783 .480 \\
\hline April & 2 & 5,08 & 15.400 & & $3.032,9 \mathrm{Kg}$ & $120,224,750$ & 115.553 .490 \\
\hline Mei & 2 & 5,16 & 16.150 & & $3.130 .1 \mathrm{Kg}$ & $122,103,250$ & 121.134 .870 \\
\hline Juni & 2 & 5,15 & 7.450 & & $1.444,3 \mathrm{Kg}$ & $56,355,750$ & 55.786 .087 .5 \\
\hline Juli & 2 & 5,14 & 7.400 & & $1.439 .4 \mathrm{Kg}$ & $56,355,750$ & 55.488 .870 \\
\hline Agustus & 2 & 5,13 & 15.700 & & $3.062,4 \mathrm{Kg}$ & $120,224,750$ & 117.136 .800 \\
\hline September & 2 & 5,10 & 16.000 & & $3.139,4 \mathrm{Kg}$ & $123,981,750$ & 120.082 .050 \\
\hline Oktober & 2 & 5,15 & 16.850 & & $3.270 .2 \mathrm{Kg}$ & $127,738,750$ & 126.311 .475 \\
\hline November & 2 & 5,16 & 17.100 & & $3.313,7 \mathrm{Kg}$ & $129,241,550$ & 128.240 .190 \\
\hline \multirow[t]{2}{*}{ Desember } & 2 & 5,15 & 18.300 & & $3.555 .2 \mathrm{Kg}$ & $139,009,750$ & 137.358 .225 \\
\hline & $24 x$ & $60 x$ & 14.379 & 2.908 & $\mathrm{Kg}$ & $1,325,854,300$ & $1.196 .721 .788,5$ \\
\hline
\end{tabular}

Berdasarkan data tabel 1 dapat dilihat perbedaan antara frekuensi dan jumlah pembelian bahan baku berdasarkan perhitungan pabrik dengan metode Economic Order Quantity (EOQ) dari bulan Januari s.d Desember 2018. Jumlah pembelian bahan baku yang selalu meningkat dari tahun ke tahun frekuensi pembelian yang telah diterapkan pabrik. rata-rata 12 kali yaitu pembelian tiap bulan sedangkan frekuensi pembelian menurut metode Economic Order Quantity(EOQ) adalah sebanyak 2 kali pemesanan hal ini akan mengefisiensi frekuensi pemesanan yang akan dilakukan.

Berbeda halnya metode EOQ memberikan dampak yang positif terhadap frekuensi pembelian akan tetapi biaya pembelian yang dikeluarkan oleh perusahaan jika menggunakan metode EOQ menjadi lebih kecil dibandingkan dengan metode konvensional yang sudah diterapkan pabrik selama ini. yaitu selisih dari penggunaan metode EOQ seperti dtunjukkan pada Tabel 2.

Tabel 2. Penerapan Metode EOQ Berdasarkan Cara Perhitungan dengan Metode EOQ

\begin{tabular}{ccc}
\hline $\begin{array}{c}\text { Pembelian menurut Pabrik Tahu } \\
\text { SKM }(\mathrm{Rp})\end{array}$ & $\begin{array}{c}\text { Pembelian Menurut } \\
\text { Metode EOQ }(\mathrm{Rp})\end{array}$ & $\begin{array}{c}\text { Selisih } \\
(\mathrm{Rp})\end{array}$ \\
\hline $1,325,854,300$ & $1.196 .721 .788,5$ & $129,132,512.5$ \\
\hline
\end{tabular}

Dari perhitungan diatas dapat diketahui bahwa Pabrik Tahu SKM dapat menghemat pembelian bahan baku kacang kedelai sebesar Rp 129.132.512,5,-

Rata-rata pembelian bahan baku selama ini yang sudah diterapkan oleh perusahaan adalah jumlah pembelian satu tahun dibagi frekuensi pembelian (12 bulan) dan hasilnya adalah ratarata pembelian setiap bulannya sebesar $14.379 \mathrm{Kg}$, Sedangkan rata-rata pembelian menurut metode EOQ hanya untuk mengukur jumlah total pembelian dan rata-rata pembelian. Berikut hasil penerapan pengendalian persediaan bahan baku kacang kedelai menurut perhitungan metode EOQ seperti ditunjukkan pada Tabel 3. 
Tabel 3. Perencanaan Persediaan Bahan Baku Dengan Metode EOQ

\begin{tabular}{cc}
\hline Metode & Hasil \\
\hline Kuantitas Pembelian & $\mathbf{2 . 9 0 8 ~ K g}$ \\
\hline Frekuensi Pembelian & $\mathbf{5}$ kali perbulan \\
\hline Persediaan Pengaman (Safety Stock) & $\mathbf{1 1 . 1 2 4 , 3 8 ~ K g}$ \\
\hline Titik Pemesan Kembali (ROP) & $\mathbf{1 0 . 2 9 3 , 7 2 ~ K g}$ \\
\hline Persediaan Maksimum (MI) & $\mathbf{R p ~} \mathbf{1 . 3 2 5 . 8 5 4 , 3 0 0}$ \\
\hline Total Biaya Persediaan &
\end{tabular}

Secara deskriptif, tabel 3 dapat dijelaskan penerapan pengendalian persediaan bahan baku yang disarankan yaitu kuantitas sebanyak $2.908 \mathrm{Kg}$ dengan Frekuensi pembelian secara konvensional yang sebaiknya dilaksanakan 5 kali perbulan. Dari perhitungan safety stock dapat kita ketahui besarnya jumlah persediaan yang dapat dicadangkan (SS) sebanyak $11.124,38$

Saat pemesanan kembali atau Reorder Point (ROP) adalah saat dimana perusahaan harus melakukan pemesanan bahan bakunya kembali agar tidak sempat kehabisan stock kacang kedelai untuk produksi.

Penentuan persediaan maksimal ini diperlukan agar jumlah persediaan yang ada di gudang tidak berlebihan, sehingga tidak menimbulkan biaya yang lebih besar untuk penyimpanan persediaan sebanyak $10.293,72 \mathrm{Kg}$.

Perhitungan total persediaan Untuk memperoleh total biaya persediaan bahan baku yang minimal maka diperhitungkan total biaya bahan baku.

\section{Kesimpulan}

Berdasarkan hasil penelitian, dapat disimpulkan bahwa analisis pengumpulan harga produksi pada Pabrik Tahu SKM di Banjarbaru dalam penetuan harga pokok masih belum sesuai teori, penulis menyarankan untuk Pabrik Tahu SKM melakukan pengumpulan harga pokok produksi menggunakan metode full codting.

2. Analisis pengendalian persediaan bahan baku dengan menggunakan Metode Economic Order Quantity ( EOQ). hasil dari penerapan metode tersebut didapat nilai EOQ dengan jumlah kuantitas sebanyak $2.908 \mathrm{Kg}$ perbulan untuk bulan Januari setiap kali melakukan pemesan dan frekuensi pemesanan sebanyak 5 kali dalam sebulan. Pengaman persediaan ( SS) bahan baku sebanyak $11.124 .38 \mathrm{Kg}$ rata rata perbulan, persediaan maksimum (MI) adalah sebanyak 10.293,72 Kg dan Total Biaya Persaediaan sebesar Rp 1.325.854.300. Penghematan atas pengendalian persediaan dengan metode EOQ adalah sebesar Rp 129,132,512.5

Berdasarkan hasil penelitian dan kesimpulan yang telah dikemukakan, dapat dibuat saran sebagai berikut:

1. Sebaiknya Pabrik Tahu SKM ini sebaiknya membuat laporan keuangan agar mempermudah perhitungan biaya produksi.

2. Pemasarannya lebih diperluas lagi, jangan hanya untuk wilayah Banjarmasin saja.

\section{DAFTAR PUSTAKA}

Diana Khairani Sofyan. Analisis Persediaan Bahan Baku Buah Kelapa Sawit Pada PT. Bahari Dwikencana Lestari. Industrial Engineering Journal Vol 6 No 1 tahun 2017. ISSN 2302 934X. 
Eidwidho Hanarista Fajrin ( 2015)“ Analisis Penegendalian Persediaan Bahan Baku Dengan Metode EOQ

Eddy Herjanto, ( 2010) Manajemen Operasi, ed: Revisi, Gramedia, Jakarta

Gusti Ayu Widi Astuti. Penerapan Metode Economic Order Quantity Persediaan Bahan Baku Pada Perusahaan Kopi Bubuk Bali Cap Banyuatis. Jurnal Pendidikan Ekonomi, Fakultas Ekonomi dan Bisnis Universitas Pendidikan Ganesha Singaraja, Indonesia Vol: 4 No: 1 Tahun 2013.

Hadari Nawawi, Metode Penelitian Bidang Sosial, Yogyakarta : gadjah Mada University Press, 1998.

Indra Mahrdhika (2018), Akuntansi Biaya , Cetakan Pertama, Quadrant, , Yogyakarta ,

V.Wiratna Sujarweni ( 2015), Akuntansi Biaya , Cetakan Pertama, Pustaka Baru Press , Yogyakarta,

Wiliam K.Carter ( 2017) Akuntansi Biaya (Cost Accounting), Edisi keempat, Salemba Empat, Jakarta . 